\title{
A correspondência de Cláudio Manuel da Costa dirigida aos acadêmicos Renascidos: informes de uma sociedade letrada*
}

\author{
The correspondence of Claudio Manuel da Costa to Renascidos academic: \\ information of a scholarly society \\ Carlos Eduardo Mendes de Moraes \\ Universidade Estadual Paulista - Assis - São Paulo - Brasil \\ Marcela Verônica da Silva \\ Universidade Estadual do Norte do Paraná - Jacarezinho - Paraná - Brasil \\ $\diamond$
}

\begin{abstract}
Resumo: Pretende-se discutir o tipo de correspondência produzida por Cláudio Manuel da Costa, na condição de membro da Academia Brasílica dos Renascidos, e comentá-la à luz da retórica antiga, apropriada pelos letrados entre os séculos XVI e XVIII como expressão modelar. Por intermédio desses documentos, comprovam-se a filiação do poeta à prática do academicismo, apresentam-se indícios de sua biografia e do domínio de dois estilos de escrita: a poética, estilo pelo qual é conhecido; e a acadêmica, empregada no exercício de suas atribuições nas associações letradas, confirmando-se suas ações tanto no quadro político quanto intelectual da época.
\end{abstract}

Palavras-chave: Cláudio Manuel da Costa; Correspondência; Academia Brasílica dos Renascidos

\begin{abstract}
In this article we intend to discuss the type of letters produced by Cláudio Manuel da Costa when he was member of Academia Brasílica dos Renascidos basing the analyses on the ancient rhetoric, used as a model by scholars between sixteenth and eighteenth century. These documents show his filiation with academicism practices, presents evidence of his biography and his domain of two writing styles: the poetic style for which he is known, and the academic style, employed in the exercise of his function under the literate associations, confirming his actions, both in the political and intellectual framework of that time.
\end{abstract}

Keywords: Cláudio Manuel da Costa; Correspondence; Academia Brasílica dos Renascidos

\section{Cartas e Epístolas}

A arte de escrever documentos ou cartas corresponde à ars dictaminis ou dictanti, conjunto de regras sistematizadas para instituir a redação de um texto formal, segundo uma prática retórica.

Para Hansen (2003, p. 18), carta e epístola possuem teor diferente: a primeira é individual e possui assunto e destinatário específico enquanto a segunda é destinada a público conhecido ou geral e disserta sobre questões doutrinárias. Entre os séculos XVI e XVIII o teor das epístolas servia a algumas funções, como, por exemplo, a de informar à pessoa ausente sobre temas específicos, eventos e lugares; reafirmar normas e posturas que

\footnotetext{
* Essa pesquisa contou com apoio da Capes/PDEE - Proc. BEX 5738/11-3.
}

deveriam ser postas em prática pelo homem de bom nível social, o Gentil-Homem; e destacar as diferenças sociais e hierárquicas entre o emissor e o destinatário da mensagem.

A estrutura da correspondência antiga possui algumas partes mais ou menos previsíveis ou fixas, entre as quais: a salutatio (saudação inicial); a capitatio benevolentiae (momento em que o remetente busca conquistar o ânimo favorável do leitor por meio de narrativas curiosas); a narratio (narração dos "fatos" de interesse do destinatário); a petitio (petição a partir de argumentos) e a conclusio (encerramento da carta).

Algumas associações letradas, notadamente entre os séculos XVI e XVIII, fizeram largo uso das epístolas, à moda dos humanistas, que retomaram o modelo latino de Cícero, assumindo nelas as qualidades de conversa 
com pessoa ausente em estilo formal, com teor voltado para temas públicos (negotialis); enquanto as cartas (familiaris) tratavam de assuntos particulares em linguagem mais informal. Comentaremos a apropriação dos modelos pelo letrado Cláudio Manuel da Costa nas referidas associações.

\section{A Academia Brasílica dos Renascidos ${ }^{1}$}

Segundo Pessoti (2009) embora os letrados reunidos em torno da segunda academia da Bahia, a dos Renascidos, não tenham lançado mão das práticas científicas em seu estágio mais avançado e se possa falar em uma defasagem entre as propostas elaboradas pelos acadêmicos e a sua concretização, é preciso considerar que o seu espaço de sociabilidade intelectual formou um campo de dinamismo e transformação científica e cultural na América portuguesa. Ainda que não tenha levado adiante todos os seus projetos, a academia contribuiu para difundir práticas e saberes que se pautaram num cientificismo permeado por máximas ilustradas ${ }^{2}$.

Em outubro de 1759 Cláudio Manuel da Costa recebeu cartas da Bahia, expedidas quatro meses antes, nas quais o secretário e dois censores da Academia Brasílica dos Renascidos o convidaram para integrá-la na qualidade de sócio supranumerário, cargo normalmente ocupado por acadêmicos que não residiam na Bahia $^{3}$.

\section{As Cartas da Academia}

As correspondências trocadas entre Cláudio Manuel da Costa e os sócios da Academia Brasílica dos Renascidos, apresentam teor formal, e, embora sejam denominadas cartas, compõem documentação sobre o cotidiano da academia. Aquelas destinadas ao censor e ao diretor da agremiação, de interesse institucional e coletivo, demonstram erudição e estilo ornado. As endereçadas aos demais sócios possuem tom mais pessoal, embora, mantenham distância adequada ao seu caráter institucional. Essa adequação de gênero nos ajuda a compreender a condição de convidado da

\footnotetext{
1 A correspondência inicialmente foi apresentada por Alberto Lamego (1923). Nelas, Cláudio Manuel da Costa anuncia o aceite ao convite recebido para tornar-se sócio e apresenta a biografia Apontamentos, além de um termo de juramento aos preceitos da academia e um texto avulso intitulado Para terminar a academia.

2 Nos estatutos da Academia Brasílica dos Renascidos, os acadêmicos supranumerários ou provinciais deveriam apresentar seus trabalhos na forma de correspondências, quando ausentes.

3 Cláudio Manuel da Costa, enquanto estudante em Coimbra frequentou as reuniões literárias dos agostinianos e dos estudantes. Na Academia Litúrgica dos Monges Agostinhos, começou a se interessar pelos círculos acadêmicos, daí a sua passagem por dois estilos distintos, o poético e o acadêmico.
}

academia reconhecido pelos serviços prestados, dentro de uma escala de valores fundamentais para integrar o grêmio.

Por intermédio das cartas, Cláudio Manuel da Costa aceitou formalmente o convite, prestou juramento aos preceitos da academia e agradeceu aos censores João Borges de Barros e João Ferreira de Bettencourt e Sá, aos sócios e ao secretário Antônio Gomes Ferrão Castelo Branco pela deferência e enviou sua biografia (um dos poucos documentos conhecidos a tratar de sua biografia). Sua tarefa seria escrever sobre sua região. Na resposta à "carta-convite", pede tempo para desempenhar a função, sob a justificativa de passar por problemas de saúde. Entretanto, mantendo a necessária formalidade, registra seu interesse, acentuado pela brevidade no tempo de resposta:

[...] apressara-se em responder por que não queria deixar sombra de dúvida sobre seu empenho em integrar aquela comunidade suprarregional; mas alertava que, daí em diante, as eventuais demoras das respostas às cartas não deveriam ser creditadas à displicência - já que se sentia honradíssimo mas, às dificuldades de comunicação, sobretudo no período das chuvas, entre Minas e a Bahia. (SOUZA, 2011, p. 148)

A importância da academia reside no fato de que as discussões das matérias diversas permitiam um avanço no registro das atividades intelectuais e letradas no solo americano. Tratava-se de questões laudatórias e políticas, defendiam-se teses sobre a flora e a fauna, sobre temas da geografia e clima e sobre aspectos históricos. Essa rede de sociabilidade letrada fixou um modelo de difusão intelectual, na qual as correspondências tiveram a sua importância capital. Os acadêmicos aprenderam a superar as distâncias, a encontrar meios de se comunicar utilizando as frotas que deixavam os portos, os comboios de comerciantes que cortavam o interior das capitanias, os correios esporádicos.

Para Souza (2011, p. 149), após a prisão de José Mascarenhas Pacheco Pereira Coelho de Melo - acusado de descumprimento das ordens de Sebastião José de Carvalho e Melo, notadamente após ter sido nomeado diretor perpétuo da Academia Brasílica dos Renascidos, que em princípio era um pretexto para arregimentar as classes privilegiadas em torno do ideal de expulsão dos jesuítas do solo português - os acadêmicos Renascidos prosseguiram mantendo contato. Cláudio Manuel da Costa, como comprovam os documentos, continuou se correspondendo com Frei Gaspar da Madre de Deus e Pedro Taques de Almeida Paes Leme. Essa correspondência se fará revelar, posteriormente, em sua obra Vila Rica, de 1773. 


\section{A Correspondência de Cláudio Manuel da Costa com a Academia}

\section{Ao secretário Antônio Gomes Ferrão Castello Branco ${ }^{4}$}

Algumas das principais cartas dirigidas aos acadêmicos, à direção e ao corpo censório da academia pelo poeta ilustram esta seção. Em carta destinada $A o$ secretário Antônio Gomes Ferrão Castello Branco, em 03 de novembro de 1759 , o poeta agradece a indicação para sócio da academia, acusando o recebimento dos estatutos e catálogos e comentando a dificuldade do intercâmbio com outras capitanias do Brasil. Constam dela a indicação das obrigações do acadêmico, os procedimentos burocráticos, a indicação dos empregos no catálogo e outras questões de igual natureza.

Aspectos que revelam uma escrita elaborada nos moldes retóricos podem ser brevemente demonstrados nesta carta. Algumas construções (p. ex. as expressões "censura do mundo" ou "aprender cegamente") significam mais do que mera demonstração de erudição, pois se trata, na verdade, de necessidade de um tratamento formal, assim como o tom laudatório (p. ex. "Feliz a América, se como se há de immortalizar nella a memória deste illustre Mecenas, se perpetuasse nella também nessa cidade a sua assistência pessoal!"). Da mesma maneira, a inclusão de seu nome entre os acadêmicos exige que a linguagem de sua correspondência oficial respeite uma hierarquia em relação à diretoria e postura adequada diante dos sócios (p. ex. "minha falta de merecimento e virtudes pessoaes, informarão melhor que a propria confissão que faço, ou o Sr. Dr. José Telles de Menezes e outros senhores mais que poderão suprir com a dilatação dos meus defeitos, aquella parte que o natural amôr me obriga a encobrir").

Alguns lugares comuns, característicos dos discursos formais apoiados na retórica antiga estão presentes: a gratidão e a humildade, dirigidas aos acadêmicos que o elegeram ("[...] faça representar a todos os senhores que em minha eleição votaram os vivos sentimentos de amôr e gratidão que eu professo"); o despertar das boas disposições de ânimo dos sócios, no caso, o "Senhor Secretário da Academia" ("possui animo benevolente"), tem a função de "preparar" o interlocutor para o conteúdo principal da carta; a tópica exordial ("Será eterna na minha memoria a lembrança deste beneficio; e com este seguro passo responder a carta de V. Mcê."); a murmuração, que não caracteriza reprovação ou posição contrária ao estado das coisas, mas consiste na alusão aos meios escassos de comunicação entre as capitanias (a resposta [da carta] "necessariamente chegará com mais demora, tanto pela dificuldade dos portadores, que são raros na occasião, como porque entrando o inverno padecem no caminho algum intervallo as mesmas Paradas do Governo"); a (falsa) modéstia (p. ex. "não entrando em dúvida de que minha falta de merecimento e virtudes pessoaes..."); o louvor à autoridade, José Mascarenhas Pacheco Pereira Coelho de Melo por meio da menção aos seus trabalhos, admirados desde a época de estudante na Universidade de Coimbra, constitui a demonstração de respeito à hierarquia, a exaltação da erudição do homenageado e, em contrapartida, a situação de destaque em que se coloca o próprio acadêmico, uma vez que sua inclusão no grêmio se justifica pela passagem pela Universidade, pelo conhecimento e reconhecimento da parte do diretor ${ }^{5}$. Essa estrutura orna o discurso baseado na retórica antiga, linguagem eleita para ser utilizada na correspondência da academia.

\section{Juramento $^{6}$}

A mesma adequação rege o cumprimento dos votos que constam do Juramento à Academia, que deve ser lido como um anexo da correspondência, pois é peça formal de ingresso. Esse documento formal associa o compromisso institucional à profissão de fé católica. $\mathrm{O}$ Juramento que Cláudio Manuel da Costa aceita e assina pode ser relacionado à carta apresentada anteriormente ao Senhor António Gomes Ferrão Castello Branco, secretário da Academia Brasílica dos Renascidos. Em ambos os documentos existem características que comprovam o caráter institucional da academia. Remete a uma prática obrigatória e formal, que associa o lado religioso ao lado cívico, constituindo ação de praxe.

\section{Apontamentos ${ }^{7}$}

Os Apontamentos, que seguem o Juramento, são documentos que dão notícia das produções escritas de Cláudio Manuel da Costa. Revelam todas as exigências da Academia para o ingresso de um novo membro. Essas exigências se alicerçavam na erudição do candidato, na estirpe nobre e no desempenho de uma função de destaque na América, características que nas práticas acadêmicas se associavam aos parâmetros de expressão da arte retórica.

A relação que se estabelece entre retórica e a formalidade da correspondência acadêmica pode se sintetizar nas orientações da Arte Retórica, de Aristóteles, acerca do bem supremo:

\footnotetext{
4 Anexo I.

5 O gênero epidítico, nessa circunstância, tem dupla função, ao louvar o interlocutor, por um lado, e evidenciar o merecimento do escritor, por outro.

6 Anexo II.

7 Anexo III.
} 
5. Um povo e uma cidade têm origem honrosa, quando seus habitantes são autóctones ou estabelecidos no solo desde há muito tempo; quando os primeiros chefes foram ilustres, ou quando daí nasceram muitos homens que se tenha ilustrado em tudo o que provoca emulação. Um particular tem origem honrosa, quer por linha masculina, quer por linha feminina. Tal origem supõe a legitimidade de ambos os lados e, do mesmo modo que no caso de uma cidade, o renome dos primeiros antepassados, no que se refere à virtude ou à riqueza ou a qualquer outra vantagem são tomadas em consideração, a ilustração de numerosos ascendentes, homens ou mulheres, jovens ou anciãos ${ }^{8}$.

Com relação a tais características, os Apontamentos (Anexo II) demonstram com clareza os aspectos apreendidos da retórica e as qualidades exigidas para o ingresso do sócio na Academia Brasílica dos Renascidos.

O documento, intitulado Apontamentos para se unir ao Catalogo da Academia Brasílica dos Renascidos, encontrados por Alberto Lamego e publicados em 1923, revelam a existência de diversos escritos de Cláudio Manuel da Costa e apresentam alguns pontos importantes no que diz respeito aos estudos sobre os modelos de escrita no Brasil Colonial, cujas referências eram a Retórica e a Poética antigas. Uma das particularidades destes textos advém do critério para aceitação dos eruditos nas agremiações e na vida pública das capitanias, característica representativa de uma formalidade que ia além das questões individuais como o grau de erudição, de competência e até de poder financeiro.

O primeiro ponto a ser destacado nesta análise é a origem de Cláudio Manuel da Costa, traçada minuciosamente pelos Apontamentos. Esses dados foram utilizados para a organização da biografia do poeta, que até a descoberta deste documento era errônea e lacunar. Os dados dos Apontamentos, além de mencionarem o seu local de nascimento, apresentam sua estirpe objeto de louvor segundo a retórica aristotélica -, o que confirma a importância do acadêmico no seu meio. Tais características mostram uma marcante preocupação com a boa procedência do futuro acadêmico.

As práticas relacionadas ao Elogio ao Soberano, além de trazerem à tona as qualidades inerentes ao homenageado, também recorrem à estirpe nobre como ponto a ser louvado. Os Apontamentos refletem estes aspectos retóricos ao evidenciarem a origem de Cláudio Manuel da Costa e suas qualidades de letrado, e esse era o requisito essencial para ingresso na agremiação baiana.

Os Apontamentos são compostos por partes fundamentais para a identificação do acadêmico. São didividas em avós paternos, maternos, irmãos, estudos, escritos e impressos. Essa hierarquia e seleção de dados esclarece bem a importância que a Academia dava às matérias dignas de serem louvadas e que constituíam o brem supremo, segundo a Retórica (Aristóteles, [s.d.]).

A divisão em família e trabalho demonstra a ordem de importância do contexto acadêmico. O que mais contribuía para a aceitação de um erudito, portanto, era a estirpe. Diante de uma exigência que estava além da pessoa do acadêmico, pode-se notar a restrição que a academia impunha ao ingresso daquele que não preenchesse o requisito. Destarte, ser chamado sócio deste grupo era uma ação para seletos.

Em seguida, listam-se os estudos, escritos e publicações. Esses dados demonstram que Cláudio Manuel da Costa possuía vasto conhecimento transformado em produção bibliográfica, aspectos indicativos de que seu nome era importante para a academia, na qual iria ocupar a função de correspondente, veiculando notícias de descobertas de sua região, as Minas, economicamente, o local de maior importância no Brasil, devido à febre do ouro. A academia, neste aspecto, demonstra preocupação com problemas econômicos, fazendo, assim, seu papel de substituto da universidade, cuja extensão era interdita para as colônias de Portugal. Os temas tratados pela Academia Brasílica dos Renascidos, assim, caminham para uma posição conformada aos anseios de Sebastião José: subtrair o poder clerical das questões administrativas, transferindo-as para o domínio político da coroa ${ }^{9}$.

\section{Outras cartas}

O tom humilde das cartas seguintes demonstra que, apesar de sua popularidade na capitania das Minas Gerais e fora dela, como poeta e homem público, advogado conceituado e secretário de governo, Cláudio Manuel da Costa, na Academia era Acadêmico e não deveria, por questões hierárquicas, ditar normas de seu trabalho, antes, deveria "aprender"10 com ela. Dentre os acadêmicos, era o único poeta e a intenção das reuniões era a de provocar discussões voltadas para a apreensão de uma

\footnotetext{
8 ARISTÓTELES. Arte retórica e arte poética. Trad. Antônio Pinto de Carvalho. Rio de Janeiro: Ediouro, [s.d.], p. 50.

9 Para traçar um paralelo entre este documento e a estrutura de um discurso epidítico, cabe dizer que a divisão processada neste texto obedece ao mesmo esquema, uma vez que demonstra uma organização que parte do geral para o particular. $\mathrm{O}$ discurso desenvolve-se a partir da origem do poeta, de sua família (âmbito geral) para sua vida e suas produções escritas (âmbito particular). Além disso, revela uma preocupação em ressaltar a procedência nobre do acadêmico, que, de acordo com a retórica, no gênero epidítico, corresponde à exaltação da estirpe. Já o esclarecimento sobre os estudos de Cláudio Manuel da Costa permitem constatar a tópica das armas e letras, na qual se destacam qualidades relativas ou à inserção do homenageado nas guerras ou à sua vocação para os estudos, ou seja, as letras.

10 O "Fundamento Histórico" do poema Vila Rica contém os aprendizados da fase acadêmica de Cláudio Manuel da Costa e revelam a ação de um grupo que, uma vez unido, deveria auxiliar no trabalho do outro, fornecendo fontes, abrindo portas para a consulta a acervos e documentos, prestando auxílio etc..
} 
história natural, eclesiástica, política etc. Deste modo, a correspondência aponta para a participação em um grupo cuja base era formada pelas relações de favor e auxílio mútuo.

$\mathrm{Na}$ carta dirigida ao censor João Borges de Barros, o teor é responder a uma possível cobrança da entrega de uma dissertação, cujo ponto principal aqui se transcreve:

Eu apezar de minhas moléstias, que segundo a ordem da natureza e do Paiz, não deixão de ser grandes e continuadas, saberei mostrar que se em mim se não acredita, ao menos não infame a eleição: darei parte dos meus estudos, communicarei as notícias que investigar, dignas de se unirem ao Corpo da Historia e praticarei finalmente segundo a qualidade de minhas forças, tudo quanto me ordena o preceito de minha muita estimada Academia.

$\mathrm{Na}$ carta ao diretor da Academia Brasílica dos Renascidos, João Borges de Barros, a retórica persiste em termos como o orgulho demonstrado pelo poeta ao ser considerado sócio entre os acadêmicos (p. ex. "Reconheço tão preciosa honra de ser lembrado sócio entre os senhores academicos da Academia Brasílica, que em credito do meu agradecimento, temo retardar esta expreção"); a tópica exordial, baseia-se na permissão do diretor/censor: (p. ex. "O distincto nome de V. Mcê. occupa o título que me authorisa...") e prossegue no exórdio louvando a sua pessoa: (p. ex. "[...] e firmando elle aquela memória de tão alto preço..."), atitude, como se viu no comentário da correspondência anterior, que permite ao poeta esperar pela fama e reconhecimento por intermédio da troca que garante o poder do homenageado e prestígio do acadêmico; é igualmente importante preservar a função do acadêmico na academia, pois Cláudio Manuel da Costa revela que apesar das suas "moléstias que segundo a ordem da natureza e do Paiz, não deixão de ser grandes e continuadas, saberei mostrar que se em mim se não acredita ao menos não infame a eleição" (LAMEGO, 1923, p. 103-104), demonstrando o grau de comprometimento existente para com os acadêmicos que o elegeram ${ }^{11}$; a conclusão reitera a falsa modéstia

\footnotetext{
11 A partir desta citação há uma maior clareza da atuação de Cláudio Manuel da Costa na agremiação. Como sócio correspondente ele deveria comunicar as pesquisas relativas à sua capitania, para fazer constar, entre as demais produções da instituição, de uma História da América Portuguesa. Além da dedicação de Cláudio Manuel da Costa à sua função da Academia Brasílica dos Renascidos, é importante frisar, também, a concomitância de ações, pois todo acadêmico possuía uma ocupação (emprego) fora da agremiação.

12 Importa observar que o conceito de censura, no ambiente das academias do século XVIII não possui conotação negativa como em nosso presente. Trata-se, a rigor, de alguma correção que se propõe a um escrito e que, prontamente e de bom grado é questionada, à guisa de esclarecimento, ou aceita, à guisa de enriquecimento do saber. Assim, o excerto da próxima carta nada tem de demérito no contexto (Anexo V).
}

como tópica no momento em que o autor se nomeia "indigno sócio", também revela a questão da hierarquia, dada à característica secundária de sua função na Academia.

Em outra carta, observa-se algum tipo de censura possivelmente a um texto de Cláudio Manuel da Costa $^{12}$ :

\begin{abstract}
Nesta parte sem duvida se encaminha a V. Mcê. a maior censura: eu que ao passo que reconheço alheia a culpa, também me considero motivo d'esta improbação, só posso dar a conhecer ao mesmo mundo que argue: que a incomparável benignidade de V. Mcê. despresa as suas censuras, quando quer fazer pompa de sua indole insaciavelmente amiga de honrar e ennobrecer e beneficiar ainda os mais indignos.
\end{abstract}

A carta destinada ao censor da Academia Brasílica dos Renascidos, o Dr. João Ferreira de Betencourt e Sá, trata do exercício da censura interna. Por ocupar na academia uma condição hierarquicamente inferior de acadêmico supranumerário, o autor assume uma posição de conformidade em relação às decisões da academia, mostrando-se agradecido e satisfeito por pertencer a uma sociedade ilustre.

Em outra carta, dirigida a todos os sócios da Academia Brasílica dos Renascidos que votaram a favor da eleição de Cláudio Manuel da Costa, há o agradecimento pelos votos que o tornaram sócio da Academia e há também expresso o compromisso do autor de executar as tarefas que lhe foram atribuídas para "não infamar a honrosa eleição" da parte dos acadêmicos. Destaquem-se alguns elogios feitos aos seus iguais:

a incomparável benignidade de V. Mcê. despresa as suas censuras, quando quer fazer pompa de sua índole insaciavelmente amiga de honrar e enobrecer e beneficiar ainda os mais indignos (...) Muito Certo e Venerador e Socio Indigno.

Com esta carta, encerra-se a troca de correspondências entre Cláudio Manuel da Costa e a Academia Brasílica dos Renascidos, anotada por Lamego (1923).

\section{Cartas não colecionadas por Alberto Lamego (1929)}

Até a produção de Lamego, em 1923, não se tinha notícia de outras cartas entre o poeta mineiro e os integrantes da Academia Brasílica dos Renascidos. Todavia, constam do acervo Arquivo Histórico Ultramarino, em Lisboa, mais duas cartas não incluídas neste rol. Provêm de Vila Rica, datadas de 3 de novembro de 1759, portanto, escritas e enviadas na mesma data das outras correspondências publicadas por Lamego. 
A primeira carta é endereçada ao censor da academia, frei Inácio de Sá e Nazaré, em que Cláudio Manuel da Costa agradece o diploma de sócio entre os acadêmicos da Academia Brasílica dos Renascidos. A carta vem com cópia do envelope com selo do "Archivo da Marinha e Ultramar"13. A segunda foi endereçada a Antônio de Oliveira ${ }^{14}$, e agradece os favores recebidos ${ }^{15}$. Essa carta revela que a admissão de Cláudio Manuel da Costa, conta provavelmente com esforços de Antônio de Oliveira, acadêmico que figura entre os mais antigos, tendo participado também da primeira academia baiana, de 1724, a Academia Brasílica dos Esquecidos.

As duas últimas cartas, não constantes da obra de lamego (op. cit.) foram transcritas e atualizadas a partir da versão microfilmada e digitalizada do original. Por se tratar de documentos importantes para a composição do ambiente letrado e intelectual da América portuguesa, foram incluídas no projeto "Resgate"16 do Arquivo Histórico Ultramarino, de Portugal, o qual permite a visualização online de documentos manuscritos relativos ao Brasil, que compreendem a documentação avulsa, os códices e as coleções de cartografia e iconografia. A transcrição deste material é importante, pois auxilia os pesquisadores da obra de Cláudio Manuel da Costa a tecer os fios de suas relações acadêmicas, além de conter informações relevantes sobre sua efetiva participação na agremiação.

\section{Considerações finais}

Pelo que se discutiu, o conceito inicial apresentado, que distingue carta de epístola, por Hansen (2003), não parece se aplicar integralmente ao caso da relação entre Cláudio Manuel da Costa e a Academia Brasílica dos Renascidos. O teor da correspondência trocada entre o acadêmico e alguns de seus sócios (iguais ou superiores na função acadêmica) demonstra o respeito a uma hierarquia, a inserção do personagem em foco, a institucionalidade da Academia, a despeito da indicação expressa do gênero "carta(s)" que dela consta.

\footnotetext{
${ }^{13}$ Segundo Lamego (1923), o Reverendo frei Ignácio de Sá e Nazareth foi examinador das ordens militares pelo supremo tribunal da Mesa de Consciência e ordens, mestre jubilado em teologia, ex-primeiro definidor da sua religião de Nossa Senhora do Carmo, reitor do Colégio de Nossa Senhora do Pilar, na cidade da Bahia e examinador no arcebispado.

${ }^{14}$ Antônio de Oliveira era mestre em artes e teólogo pelos estudos gerais do Brasil e muitas vezes exerceu a função de examinador de filosofia. Foi missionário apostólico e duas vezes visitador do arcebispado, "com poderes de chrismar, por indulto do pontífice Benedicto XIV" (LAMEGO, 1923, p. 11). Também participou da Academia Brasílica dos Esquecidos.

15 AHU - Inventário 6052 - AHU, MG, Cx. 74, Doc. 35 - AHU-CU-011 Cx. 74, D. 6177- Rolo 65 (1-74).

16 A consulta a documentos do Projeto Resgate do Arquivo Histórico Ultramarino pode ser feita pelo sítio <http://www.cmd.unb.br/resgate_ index.php>.
}

A questão de discussão de uma doutrina não parece ser clara, embora esteja implícita em todo o estabelecimento das regras de funcionamento da Academia ditadas tanto pelos estatutos mencionados, como pela distribuição dos empregos, pelo juramento, pelos apontamentos, que, mais do que uma mera troca de missivas entre homens letrados, compõe toda a estrutura que manteve o acervo relativo à Academia Brasílica dos Renascidos agrupado em torno de uma proposta de existência de uma instituição que, embora extraoficial, do ponto de vista do reconhecimento da Coroa portuguesa, marca uma transformação significativa no pensamento e na expressão histórica, científica, letrada e até mesmo econômica no espaço lusoamericano da segunda metade do século XVIII.

Nesse contexto, o conhecido poeta Cláudio Manuel da Costa tem a sua expressão de expoente da literatura brasileira relegada a um plano menor. A sua obra importa enquanto forma de admissão no grêmio. Todavia, uma vez que Cláudio Manuel da Costa tenha sido admitido, os escritos que documentam a sua ação na Academia, principalmente a correspondência, demonstram uma hierarquia na qual importa mais a função de acadêmico do que o fazer do poeta.

\section{Referências}

ALCIDES, Sérgio. Estes penhascos: Cláudio Manuel da Costa e a paisagem das Minas. São Paulo: Hucitec, 2003.

ALCIDES, Sérgio. O lugar não comum e a república das letras. In: Revista do arquivo público mineiro, ano XLIV, n. 2, jul./dez. 2008.

ARISTÓTELES. Arte retórica e arte poética. São Paulo: Abril, 2005.

BARTHES, Roland. A retórica antiga. In: COHEN, Jean et alii. In: Pesquisas de retórica. Rio de Janeiro: Vozes, 1975.

CARDOZO, Alírio; CHAMBOULEYRON, Rafael. A pena e a espada. Retórica e história nas cartas de um governador do século XVIII. Revista Outros Tempos, v. 5, n. 5, jun. 2008.

PROENÇA FILHO, Domício (Org.). A poesia dos Inconfidentes. Rio de Janeiro: Nova Aguilar, 1996.

CURTIUS, Ernst Robert. Literatura européia e idade média. Trad. Teodoro Cabral e Paulo Rónai. São Paulo: HucitecEDUSP, 1996.

ESTATUTOS da Academia Brazilica dos Renascidos estabelecida na cidade do Salvador, Bahia de Todos os Santos, Capital de Toda a America Portugueza da qual ha de escrever a historia universal. In: Revista do Instituto Histórico e Geográfico Brasileiro, Rio de Janeiro, IHBG, [ ].

HANSEN, João Adolfo. “Cartas de Antônio Vieira (1626-1697). In: HANSEN, João Adolfo (Org.). Vieira, Antônio. Cartas do Brasil. 1626-1697. Estado do Brasil e Estado do Maranhão e Grã Pará. São Paulo: Hedra, 2003.

HATZFELD, Helmut. Estudos sobre o Barroco. Trad. Célia Barrettini. São Paulo: Perspectiva, 1988. 
KANTOR, Íris. Esquecidos e renascidos. São Paulo: Hucitec, 2004.

LAMEGO, Alberto. A Academia Brazilica dos Renascidos. Paris: E`Edition d`art gáudio, 1923.

LAUSBERG, Heinrich. Elementos de retórica literária. Lisboa: Calouste Gulbenkian, 1967.

PESSOTI, Bruno Casseb. Ajuntar manuscritos, e convocar escritores: o discurso histórico institucional no setecentos lusobrasileiro. Salvador, 2009. Dissertação (Mestrado em História) - Faculdade de Filosofia e Ciências Humanas da Universidade Federal da Bahia.

QUINTILIANO, M. Fábio. Instituições oratórias. São Paulo: Edições Cultura, 1944.

ROCHA, Andrée. Epistolografia em Portugal. Lisboa: Imprensa Nacional, 1985.
SILVA, Marcela Verônica da. Constância da retórica, mudança de estilo: a obra acadêmica de Cláudio Manuel da Costa. Assis, 2009. Dissertação (Mestrado em Literatura Brasileira) - Faculdade de Ciências e Letras da Universidade Estadual Paulista.

SILVA, Marcela Verônica da. O poema "Vila Rica" e seu Fundamento Histórico: engenho do poeta e arte do letrado. Assis, 2013. Tese (Doutorado em Literatura Brasileira) - Faculdade de Ciências e Letras da Universidade Estadual Paulista.

SOUZA, Laura de Mello e. Cláudio Manuel da Costa. O letrado dividido. São Paulo: Companhia das Letras, 2011.

SOUZA, Laura de Mello e. O antigo e o moderno na obra de Cláudio Manuel da Costa. In: Revista de História, São Paulo, 2010. Disponível em: <http://www.revistasusp.sibi.usp.br/ scielo.php?pid $=$ S0034-83092010000300007\& script $=$ sci arttext>. Acesso em> 19 dez. 2012.

\section{ANEXOS}

\section{ANEXO I \\ Carta de Cláudio Manuel da Costa ao Secretário da Academia Brazilica dos Renascidos}

Snr. Sargento-Mór Antônio Gosmes Ferrão Castello Branco Depois de fazer manifesto ao Sr. Director da minha muito prezada Academia dos Renascidos quanto eu era agradecido á inestimavel honra de ser chamado socio de tão disticto congresso, não contento com pedir ao mesmo senhor faça representar a todos os senhores que em minha eleição votaram, os vivos sentimentos de amôr e gratidão que eu professo, não sei se menos á igualdade que ao favôr de seus votos. Especialmente devo fazer a V. Mcê, esta expressão que dignando-se a ter tão grande parte neste empenho, menos temem incorrer na censura do mundo, que recatar a benevolência de seu animo: será eterna na minha memoria a lembrança deste beneficio; e com este seguro passo responder a carta de V. Mcê.

No ultimo de Outubro, me foi entregue a preciosa noticia de V. Mcê. que fora escripta com data de 15 de Junho, a remessa do Rio para essa capital, não deixou de ser com diligência, porque o cavalheiro que a recebeu á 15, com a chegada da embarcação, a fez enviar no dia 16 do mesmo mez; a resposta necessariamente chegará com mais demora, tanto pela dificuldade dos portadores, que são raros na occasião, como porque entrando o inverno padecem no caminho algum intervallo as mesmas Paradas do Governo.

Com esta prevenção asseguro á $V$. Mcê, de que a dilação que occorrer não só na presente como em outra qualquer conjectura se não deverá tanto atribuir ao meu descuido quanto a ordinária contingência dos successos. Recebo os Estatutos e catálogos da minha muito prezada Academia e tudo quanto em hua e outra disposição advirto hé hum authentico testemunho da prudente circumspecção do seu egrégio Director, eu tive a honra de admirar na Universidade os incomparaveis creditos que este senhor adquiria com os seus grandes estudos; e agora acabo de conhecer que elle dirigiu as sciencias a seu verdadeiro fim, que he a utilidade publica.

Feliz a América, se como se há de immortalizar nella a memória deste illustre Mecenas, se perpetuasse nella também nessa cidade a sua assistência pessoal!

Nada teriamos que invejar nem os Porticos d'Athenas nem aos Templos do Egipto.

Em observancia do preceito, tudo aprovo, tudo admiro e respeito tudo.

Pede mais alta e prudente averiguação que fizer e de algumas lembranças ou documentos que nestas Minas se guardarem, fazer communicar á $V$. Mcê. As cópias ou os originaes na fórma de sua recommendacão.

A esta acompanha o juramento, não sei se com a solemnidade precisa; mas devendo-se em tal ponto attender, somente a validade e substancia do acto, ocioso se faz escrupulisar sobre a formalidade das palavras: sendo porem do voto dos Srs. Academicos, terá V. Mcê. a bondade de me communicar a norma; que quem principia a aprender cegamente obedece aos dictames que venera.

Finalmente, por me conformar com a disposição do $\S 6^{\circ}$ dou a V. Mcê. estes apontamentos, não entrando em duvida, de que da minha falta de merecimento e virtudes pessoaes, informarão melhor que a propria confissão que faço, as noticias de alguns contemporaneos, hoje socios meus com grande vaidade, na minha muito presada Academia. Hé o primeiro o Sr. director que em sua carta se dignou honrar-me com este titulo: o Sr. Dr. José Telles de Menezes e outros senhores mais que poderão suprir com a dilatação dos meus defeitos, aquella parte que o natural amôr me obriga a encobrir.

Toda occasião que $V$. Mcê. tiver de honrar-me no seu serviço será para mim estimada e eu teria a honra de confessar que sou de V. Mcê. muito affectuoso socio.

Vila Rica, 3 de Nov. 1759. Cláudio Manuel da Costa. (LAMEGO, 1923, p. 98-100) 


\section{ANEXO II}

Juramento

O Bacharel Cláudio Manuel da Costa, Advogado nos Auditórios de Villa Rica de Ouro Preto, Academico Supranumerario da Academia Brazilica dos Renascidos.

Por este por mim feito e assignado em observância dos Estatutos da minha muito presada Academia e particularmente do que se dispõem no $\$ 17$, juro e protesto inviolavelmente defender a verdade da Immaculada Conceição da Virgem May de Deos e de sujeitar-me em tudo aos preceitos da mesma Academia, segundo o Titolo que me foi conferido. Cláudio Manuel da Costa. (LAMEGO, 1923, p. 100-101)

\section{ANEXO III}

\section{Apontamentos para se unir ao catálogo de acadêmicos da Academia Brazilica dos Renascidos}

Cláudio Manuel da Costa, filho de João Gonçalves da Costa e de D. Theresa Ribeyro de Alvarenga.

Nasceu aos 5 de Junho de 1729 no bispado de Marianna em hum dos districtos da cidade chamado a Vargem; onde viviam situados seus Pais em o exercicio de minerar e plantar segundo o uso do Paiz.

Seus avós pela parte paterna: Antônio Gonçalves e Antônio Fernandes, moradores que forão no lugar das Áreas, Freguezia de S. Mamede das Talhadas, Bispado de Coimbra.

Pela parte materna: O capitão Francisco de Barros Freire e D. Izabel Rodrigues de Alvarenga, moradores que foram na Freguezia de N. S. de Guarápiranga, Comarca do Ribeirão do Carmo, hoje cidade de Marianna, vindos de S. Paulo onde têm á sua ascendência de Famílias mui distinctas.

Seus Irmãos: De legitimo matrimonio teve cinco irmãos dos quaes foi elle o 3 o. na ordem da sucessão e quatro cursarão a Universidade e se achão hoje recolhidos a Religiosos dois: o Padre Antônio de Santa Maria dos Martires no Réal Mosteiro da Santa Cruz de Coimbra, o Padre Frei Francisco de Salles de Jesus Maria, no collegio da Trindade que actualmente segue a Universidade: morreu na mesma Universidade o segundo que se chama João Antônio da Costa. Os mais acompanham hoje a familia.

Seus estudos: Principiou a grammática e estudos de Latinidade debaixo da proteccão do seu tio o Dr. Frei Francisco Vieira, Oppositor que foi na Faculdade de Coimbra, hoje Procurador geral da Religiam da Santíssima Trindade no Estado do Brasil. Assistio os primeiros quatorze ou 15 annos em Villa Rica de Ouro Preto; passou a estudar Philosophia na Companhia do Rio de Janeiro; donde embarcou na héra de 49 para Lisboa: formouse em Coimbra na Faculdade de Canones, em que lhe foi presente o Sr. Christovam de Almeida. Na héra de 53 para 54 se recolheu á sua Patria, onde vive no exercicio de advogado: com actual assistência em Villa Rica de Ouro Preto.

Seus escriptos:

Applicado desde os primeiros annos ao estudo das Bellas Letras conserva em Manuscriptos Rithmas nas línguas Latina, Italiana, Portugueza, Castelhana e Franceza em poesia heroica e lirica dois tomos em 4.

Rythmas pastoris com o titulo de Musa Bucolica, duas partes em 40.

Centúria Sacra, Poema do Glorioso Parto de Maria Santissima em 8 a Rythma.

Cathaneida, Poema joco-serio em 5 cantos e 8a Rythma.

Varios discursos em prosa em diversas materias

Poesias dramáticas que se tem muitas vezes representado nos theatros de Vila Rica, Minas em geral e Rio de Janeiro.

Mafalda Triunphante que se mandou imprimir e foi composta a empenho do Exmo. Sr. Bispo desta Diocese a quem é dedicada.

Cyro ou a liberdade de Camboydes.

Circe e Ulysses: Orlando furioso; Siques e Cupido em Rithma solta, calipso.

Varias traduccões dos dramas do Abbade Pedro Metastasio: o Ataxerxes, a dircea, O Demetrio, O José Reconhecido, O sacrifício de Abrahão, o Regulo, o Parnaso Accusado: Alguns destes dramas em rithma solta, outros em prosa proporcionados ao theatro português.

Papeis impressos:

Correm impressos na Universidade de Coimbra: O Monusculo Métrico.

$O$ Epicedio á morte de Fr. Gaspar da Encarnação.

O Culto Métrico a hua Abadeça do Convento de Figueiró.

As suas conclusões em Canones, com hua dedicatória deduzidas dos versos de Virgilio.

Da-se noticia somente das Rythmas e Obras que se achão limadas em termos de se darem ao prelo se convier ao seu A, sendo muitos mais os papeis de que não faz menção. (LAMEGO, 1923, p. 102-103) 


\section{ANEXO IV}

Carta

Ao Muito Rev. Sr, Dr. João Borges de Barros, Digníssimo Censor da Academia Brasilica dos Renascidos, Bahia. Do Academico Cláudio Manuel da Costa.

Muito Revm. Sr. Sr. Dr. João Borges de Barros.

Reconheço tão preciosa honra de ser lembrado sócio entre os senhores Academicos da Academia Brasilica, que em credito do meu agradecimento, temo retardar esta expreção.

$O$ distincto nome de V. Mcê. occupa o Título que me authorisa e firmando elle aquella memória de tão alto preço, deixa talvez menos viva no Instrumento, a impressão que da minha vontade o caracter que me dará a conhecer ao mundo sempre reverente e sempre obrigado.

Eu apezar de minhas moléstias, que segundo a ordem da natureza e do Paiz, não deixão de ser grandes e continuadas, saberei mostrar que se em mim se não acredita, ao menos não infame a eleição: darei parte dos meus estudos, communicarei as notícias que investigar, dignas de se unirem ao Corpo da Historia e praticarei finalmente segundo a qualidade de minhas forças, tudo quanto me ordena o preceito de minha muita estimada Academia.

Significo a V. Mcê. o mais terno affecto com o qual sou de V. Mcê. humilde, se indigno socio.

Claudio Manuel da Costa.

Vila Rica, 3 de Novembro de 1759. (LAMEGO, 1923, p. 103-104)

\section{ANEXO V}

Carta

Ao Sr. Dr, João Ferreira de Betencourt e Sá, Digníssimo Censor da Academia dos Renascidos.

Bahia. Do Academico Claudio Manuel da Costa, Sr. Dr. João Ferreira Betencourt e Sá.

Eu me persuado, que sem esta expreção ficarei devedor ao mundo de hua generosa satisfação quando no egrégio titulo de supra numerário, com que me honra a eleição dos senhores acadêmicos, vejo particularmente firmado o precioso e distincto nome de V. Mcê.: conhece o mundo meu demérito, estranha condemna e talvez argue de menos iguaes os votos de hum tão ajustado congresso. Nesta parte sem duvida se encaminha a V. Mcê. a maior censura: eu que ao passo que reconheço alheia a culpa, também me considero motivo d'esta improbação, só posso dar a conhecer a mesmo mundo que argue: que a incomparável benignidade de V. Mcê. despresa as suas censuras, quando quer fazer pompa de sua indole insaciavelmente amiga de honrar e ennobrecer e beneficiar ainda os mais indignos: no número destes me reconhecerei eu sempre, confessando que sou de V. Mcê. Muito Certo e Venerador e Socio Indigno. Claudio Manuel da Costa.

Novembro, 3 de 1759 em Villa Rica. (LAMEGO, 1923, p. 104-105)

\section{ANEXO VI}

\section{Carta}

Aos Senhores Academicos da Academia Brasilica dos Renascidos, na cidade de S. Salvador. Bahia.

Do Academico Claudio Manuel da Costa:

Senhores sócios da Academia Brasilica.

Quisera distintamente gratificar a cada hum de V. Mcês. a preciosissima honra de que me fizerão digno no concurso de seus votos: eu conheço os excessos de gloria que este grão me communica; e quanto eu posso, farei por dar a conhecer ao mundo, que procurarei com todas as minhas forças, não infamar a honrosa eleição de $V$. Mcês.

Faço remetter ao Sr. Secretario o meu juramento que como se presente estivesse, rogo a V. Mcês. o hajão por valido, com todas as forças que a minha muito prezada Academia aprova e costuma solenizar este grande acto; $e$ venerando com profundo respeito todos os seus Estatutos, faço também com as mesmas forsas todas as protestações devidas, em signal de que aceito a grande honra que V. Mcês. me conferem de acadêmico supra-numerario em cujo emprego e no serviço de V. Mcês. viverei sempre prompto.

Villa Rica 3 de Novembro de 1759.

O Academico supra numerario.

Claudio Manuel da Costa. (LAMEGO, 1923, p. 105) 


\section{ANEXO VII}

Muito Reverendo Senhor Frei Ignácio de Sá e Nazareth. ${ }^{17}$

Tem firmado por [Vossa Reverendíssima] o egrégio título, que me dá o caráter de Sócio entre os Senhores Acadêmicos da Academia Brasílica; e reconhecendo ser tão destituída a minha pessoa de merecimentos, tão superior o emprego, mal posso deixar de examinar algum meio com que se [dissimule empregar] minhas indignidades: confesso não haver outro mais ajustado que o confessá-la; e se é tão cega, e pronta a minha obediência em aceitar a eleição, desculpa me devem dar o excesso da honra a que sou chamado, e o poderoso domínio, que tem nas vontades de todos um Congresso tão distinto: igualmente neste ponto se faz benemérita a ambição e a obediência.

Fica a meu cargo mostrar a [Vossa Reverendissima] em todo o tempo, que se não perde no meu agradecimento esta honrosa memória; e quanto [ma] tem de grande na minha estimação terá de infinita a condição que faço de que [sócio].

De [Vossa Reverendíssima]

O mais humilde [Vassalo] e Sócio.

Cláudio Manuel da Costa

Vila Rica, 3 de novembro de 1759.

\section{ANEXO VIII}

Muito Reverendo Senhor Antônio de Oliveira

Gratifico a [Vossa Mercê] a lembrança com que se dignou honrar-me, associando a [minha] indigna pessoa aos distintos Senhores desse Congresso: Eu terei sempre viva [para] meu agradecimento à memória desta atenção; e quanto cabe na inutilidade de meus desejos ofereço a disposição de [Vossa Mercê].

[Desejo ter ocasiões] de mostrar repetidas vezes que sou.

[Reverendissimo]

Muito humilde [...] sócio.

Cláudio Manuel da Costa

Vila Rica 3 de novembro de 1759.

Recebido: 22 de outubro de 2013

Aprovado: 18 de novembro de 2013

Contato: mendesdemoraes@yahoo.com.br; maveronica83@yahoo.com.br

${ }^{17}$ AHU 2698 - Inventário 6041 - AHU-MG-Cx 74 Doc. 34 - D 6176 - Rolo 65 (1-74). 